\title{
Bladder Urothelial Dysplasia
}

National Cancer Institute

\section{Source}

National Cancer Institute. Bladder Urothelial Dysplasia. NCI Thesaurus. Code C27882.

Intraurothelial neoplasia characterized by dysplastic changes which are not severe

enough to warrant the diagnosis of bladder carcinoma in situ. -- 2003 